\title{
Delftia acidovorans: A rare pathogen in immunocompetent and immunocompromised patients
}

\author{
Huseyin Bilgin $M D^{1}$, Abdurrahman Sarmis $M D^{2}$, Elif Tigen $M D^{1}$, Guner Soyletir MD², Lutfiye Mulazimoglu MD ${ }^{1}$
}

H Bilgin, A Sarmis, E Tigen, G Soyletir, L Mulazimoglu. Delftia acidovorans: A rare pathogen in immunocompetent and immunocompromised patients. Can J Infect Dis Med Microbiol 2015;26(5):277-279.

Delftia acidovorans is an aerobic, nonfermenting Gram-negative bacillus. It is usually a nonpathogenic environmental organism and is rarely clinically significant. Although $D$ acidovorans infection most commonly occurs in hospitalized or immunocompromised patients, there are also several reports documenting the infection in immunocompetent patients. The present article describes a B cell lymphoblastic leukemia patient with $D$ acidovorans pneumonia who was successfully treated with antibiotic therapy. The present report indicates that unusual pathogens may be clinically significant in both immunocompromised and immunocompetent patients. $D$ acidovorans is often resistant to aminoglycosides; therefore, rapid detection of this microorganism is important.

Key Words: Delftia acidovorans; Febrile neutropenia; Immunocompromised; Pneumonia

\section{CASE PRESENTATION}

A 68-year-old woman with an unremarkable medical history who had been diagnosed with B cell acute lymphocytic leukemia was admitted to the hematology clinic to undergo chemotherapy. Three days before admission, she developed cough, purulent sputum and dyspnea without fever. She had not been admitted to the hospital or have a history of antibiotic use within the previous three months.

On examination, her body temperature was $36^{\circ} \mathrm{C}$, with a blood pressure of $105 / 50 \mathrm{mmHg}$, a heart rate of 80 beats/min, a respiratory rate of 30 breaths/min and oxygen saturation of $88 \%$ on room air. Breath sounds were coarse, with bilateral rales. Her physical examination was otherwise unremarkable. A computed tomography scan of her lungs revealed areas of consolidation suggesting pneumonia. On admission, she was started on intravenous piperacillin-tazobactam, 4.5 g every $6 \mathrm{~h}$, ciprofloxacin, $400 \mathrm{mg}$ every $12 \mathrm{~h}$, as well as vincristine and prednisolone. Blood, urine and sputum cultures were negative.

On day 6 , she became neutropenic. Hypoxemia, cough and sputum improved on day 14. Elevated C-reactive protein and procalcitonin levels decreased substantially. Antibiotics were discontinued. Meanwhile, treatment with imatinib was initiated.

On day 17, her initial symptoms recurred and a computed tomography scan revealed progression of previous consolidation areas. Serial serum galactomannan antigen tests were negative. Sputum cultures were obtained and piperacillin-tazobactam and ciprofloxacin were started again. Blood cultures were not repeated because the patient was afebrile.

\section{Le Delftia acidovorans: un agent pathogène rare chez les patients immunocompétents et immunodéprimés}

Le Delftia acidovorans est un bacille aérobie à Gram négatif sans pouvoir de fermentation. C'est un organisme généralement non pathogène présent dans l'environnement, qui est rarement significatif sur le plan clinique. Même si l'infection à $D$ acidovorans s'observe surtout chez des patients hospitalisés ou immunodéprimés, plusieurs rapports le signalent chez des patients immunocompétents. Le présent article décrit un patient atteint d'une leucémie lymphoïde de type $\mathrm{B}$ compliquée par une pneumonie à $D$ acidovorans éradiquée par antibiothérapie. D'après le présent rapport, des agents pathogènes inhabituels peuvent être cliniquement significatifs à la fois chez les patients immunodéprimés et chez les patients immunocompétents. Puisque le $D$ acidovorans résiste souvent aux aminosides, il est important de le déceler rapidement.

\footnotetext{
${ }^{1}$ Marmara University School of Medicine, Infectious Diseases and Clinical Microbiology, ${ }^{2}$ Marmara University School of Medicine, Department of Microbiology, Istanbul, Turkey

Correspondence: Dr Huseyin Bilgin, Marmara Universitesi, Pendik Egitim ve Arastirma Hastanesi, Enfeksiyon Hastaliklari Anabilim Dali, Fevzi Cakmak Mah. Mimar Sinan Cad. No: 41 Ust Kaynarcal Pendik 34896, Istanbul, Turkey.

Telephone 90216625 4693, fax 902166254790 e-mail husambilginer@gmail.com, huseyin.bilgin@marmara.edu.tr
} 
TABLE 1

Summary of Delftia acidovorans infections according to infection site

\begin{tabular}{|c|c|c|c|c|c|}
\hline Reference & Age, years & Infection & Risk factor(s) & Treatment & Outcome successful \\
\hline Present case & 68 & Nosocomial pneumonia & Hematological malignancy & IV piperacillin/tazobactam & Yes \\
\hline 2 & 79 & $\begin{array}{l}\text { Nosocomial pneumonia } \\
\text { and bacteremia }\end{array}$ & $\begin{array}{l}\text { Chronic obstructive pulmonary } \\
\text { disease }\end{array}$ & IV meropenem & No \\
\hline 4 & 4 & Empyema & Immunocompetent & IV cefaperazone/sulbactam & No \\
\hline 5 & 5 & Empyema & Immunocompetent & IV imipenem & Yes \\
\hline 6 & 11 & CRBSI & Solid organ malignancy & Catheter removal and IV ceftazidime & Yes \\
\hline 8 & 4 & CRBSI & Solid organ malignancy & IV ceftazidime & Yes \\
\hline 9 & 27 & CRBSI & AIDS & Catheter removal, IV imipenem and amikacin & Yes \\
\hline 10 & 65 & CRBSI & Hematologic malignancy & Catheter removal and IV imipenem & Yes \\
\hline 11 & 10 & CRBSI & $\begin{array}{l}\text { End-stage renal disease and } \\
\text { hemodialysis }\end{array}$ & Cahteter removal and IV cefepime & Yes \\
\hline 12 & 42 & Infective endocarditis & Intravenous drug use & IV ceftazidime and ciprofloxacin & No \\
\hline 15 & 49 & Keratitis & $\begin{array}{l}\text { Corticosteroid treatment and } \\
\text { corneal transplantation }\end{array}$ & Topical and IV ceftazidime & No \\
\hline 16 & Unknown & Ocular infections & Unknown & Unknown & Unknown \\
\hline 17 & 40 & Keratitis & Hyrdogel contact lenses & IV gentamicin and ciprofloxacin & Yes \\
\hline 18 & 61 & Urinary tract infection & Immunocompetent & Oral norfloxacin & Yes \\
\hline 19 & 46 & Bacteremia & Immunocompetent & IV piperacillin/tazobactam & Yes \\
\hline 22 & Unknown & Bacteremia & Pressure-monitoring device & Unknown & Unknown \\
\hline 23 & 93 & Bacteremia & Immunocompetent & IV imipenem/cilastatin & Yes \\
\hline 24 & 30 & Bacteremia & Immunocompetent & IV piperacillin/tazobactam & Yes \\
\hline
\end{tabular}

CRBSI Catheter-related bacteremia; IV Intravenous

Three cases involving nosocomial pulmonary infections have been reported in the literature. Franzietti et al (3) reported an episode of nosocomial pneumonia as an opportunistic infection in a patient with AIDS. The organism was isolated from bronchoalveolar lavage fluid and the patient responded to ceftazidime treatment. Khan et al (4) reported a case involving a four-year-old immunocompetent child with empyema. $D$ acidovorans was isolated from the drainage tube and the endotracheal aspirate sample. The patient did not survive, despite cefaperazone-sulbactam treatment. Chun et al (5) reported a chronic empyema case associated with $D$ acidovorans in an immunocompetent adult patient.

Although rare, $D$ acidovorans infection can be clinically important in immunocompromised patients with underlying malignancies, such as chronic kidney disease, HIV/AIDS (2) or patients taking immunosuppressive drugs. However, serious infections with $D$ acidovorans have also been reported in immunocompetent patients $(4,5,18,19,20)$.

The susceptibility profile of our isolate was similar to strains in previous reports (10-13).

Identification of the microorganism can be performed using a simple orange indole reaction test. With the addition of Kovac's reagent, the organism produces anthranilic acid using tryptophan. This results in a pumpkin-orange colour in the media, which is characteristic for $D$ acidovorans (4)

An extensive literature search revealed several other cases of $D$ acidovorans infection (Table 1 ).

Because of the ubiquitous presence of this microorganism, establishing its pathogenicity may be difficult. In the present case, clinical and radiological signs led us to a diagnosis of pneumonia, and the patient improved with antibiotic therapy. At that time, there was a large outbreak with carbapenem-resistant Enterobactericea in the medical and surgical intensive care units. We performed surveillance cultures in the hematology unit, and in the medical and surgical intensive care units. We did not isolate this microorganism from any environmental or patient cultures. Therefore, we accepted the organism as a pathogen in the present case.

A recent study performed in an intensive care unit in Brazil (21) showed clonal dissemination of $D$ acidovorans in hospital settings using molecular confirmation. They isolated $24 \mathrm{D}$ acidovorans strains in 21 patients from deep tracheal aspirate samples. However, they could not decide on the clinical significance of the pathogen due to lack of clinical data and patient follow-up.

$D$ acidovorans-related infections are rare. It can occur in different age groups, as well as in both immunocompromised and immunocompetent patients (3-14). D acidovorans is often resistant to aminoglycosides (20), which are commonly used as empirical treatments in febrile neutropenic patients and in most Gram-negative infections. Therefore, timely identification of this organism to the species level is necessary to determine the most appropriate antibiotic therapy.

ACKNOWLEDGEMENTS: Editing assistance was provided by PulsusEdit, Oakville, Ontario.

\section{REFERENCES}

1. Forbes B, Sahm D, Weissfeld A. Alcalgenes, Bordetella, Comamonas and similar organisms. In: Bailey\&Scott's Diagnostic Microbiology, 12th edn. St Louis: Elsevier, 2007:363-70.

2. Taş T, Küçükbayrak A, Koçoğlu E, et al. Nosocomial pneumonia and bacteremia caused by Delftia acidovorans related to arterial catheter. Dicle Medl J 2012;39:452-4.

3. Franzetti F, Cernuschi M, Esposito R, Moroni M. Pseudomonas infections in patients with AIDS and AIDS related complex. J Int Med 1992;231:437-43. 
4. Khan S, Sistla S, Dhodapkar R, Parija SC. Fatal Delftia acidovorans infection in an immunocompetent patient with empyema. Asian Pac J Trop Biomed 2012;2:923.

5. Chun J, Lee J, Bae J et al. Delftia acidovorans isolated from the drainage in an immunocompetent patient with empyema. Tuberc Respir Dis 2009;67:239-43.

6. Kawamura I, Yagi T, Hatakeyama K, et al. Recurrent vascular catheter-related bacteremia caused by Delftia acidovorans with different antimicrobial susceptibility profiles. J Infect Chemother 2010;17:111-3.

7. Castagnola E, Tasso L, Conte M, Nantron M, Barretta A, Giacchino R. Central venous catheter-related Comamonas acidovorans infection in a child with non-Hodgkin's lymphoma. Clin Infect Dis 1994;19:559-60.

8. Ender PT, Dooley DP, Moore RH. Vascular catheter-related Comamonas acidovorans bacteremia managed with preservation of the catheter. Pediatr Infect Dis J 1996;15:918-20.

9. Lair MI, Bentolila S, Grenet D, Cahen P, Honderlick P. Oerskovia turbata and Comamonas acidovorans bacteremia in a patient with AIDS. Eur J Clin Microbiol Infect Dis 1996;15:424-6.

10. Lang KJ, Chinzowu T, Cann KJ. Delftia acidovorans as an unusual causative organism in line-related sepsis. Indian J Microbiol 2012;52:102-3.

11. Chotikanatis K, Bäcker M, Rosas-Garcia G, Hammerschlag MR. Recurrent intravascular-catheter-related bacteremia caused by Delftia acidovorans in a hemodialysis patient. J Clin Microbiol 2011;49:3418-21.

12. Horowitz H, Gilroy S, Feinstein S, Gilardi G. Endocarditis associated with Comamonas acidovorans. J Clin Microbiol 1990:28;143-5.

13. Mahmood S, Taylor KE, Overman TL, McCormick MI. Acute infective endocarditis caused by Delftia acidovorans, a rare pathogen complicating intravenous drug use. J Clin Microbiol 2012;50:3799-800.

14. López-Menchero R, Sigüenza F, Caridad A, Alonso JC, Ferreruela RM. Peritonitis due to Comamonas acidovorans in a CAPD patient. Perit Dial Int 1998;18:445-56.
15. Lee SM, Kim MK, Lee JL, Wee WR, Lee JH. Experience of Comamonas acidovorans keratitis with delayed onset and treatment response in immunocompromised cornea. Korean J Ophthalmol 2008;22:49-52.

16. Stonecipher KG, Jensen HG, Kastl PR, Faulkner A, Rowsey JJ. Ocular infections associated with Comamonas acidovorans. Am J Ophthalmol 1991;12:46-9.

17. Lema I, Go'mez-Torreiro M, Rodríguez-Ares MT. Comamonas acidovorans keratitis in a hydrogel contact lens wearer. CLAO J 2001;27:55-6.

18. del Mar Ojeda-Vargas M, Suárez-Alonso A, de Los Angeles PérezCervantes M, Suárez-Gil E, Monzón-Moreno C. Urinary tract infection associated with Comamonas acidovorans. Clin Microbiol Infect 1999;5:443-4.

19. Hagiya H, Murase T, Sugiyama J, et al. Delftia acidovorans bacteremia caused by bacterial translocation after organophosphorus poisoning in an immunocompetent adult patient. J Infect Chemother 2013;19:338-41

20. Lipuma JJ, Currie BJ, Peacock SJ, Vandamme P, Whittier S. Burkholderia, Cupriavidus, Pandoraea, Stenotrophomonas, Ralstonia, Brevundimonas, Comamonas, Delftia, and Acidovorax. In: Versalovic J, et al, eds, Manual of Clinical Microbiology, 10th edn. Washington, DC: ASM Press, 2011:692-713.

21. Camargo CH, Ferreria AM, Javaroni E, et al. Microbiological characterization of Delftia acidovorans clinical isolates from patients in an intensive care unit in Brazil. Diagn Microbiol Infect Dis 2014;80:330-3

22. Weinstein RA, Stamm WE, Kramer L, Corey L. Pressure monitoring devices. Overlooked source of nosocomial infection. JAMA 1976;236:936-8.

23. Kam SK, Lee WS, Ou TY, Teng SO, Chen FL. Delftia acidovorans bacteremia associated with ascending urinary tract infections proved by molecular method. J Exp Clin Med 2012;4:180-2.

24. Oliver JW, Stapenhorst D, Warraich I, Griswold JA. Ochroboctrum anthropi and Delftia acidovorans to bacteremia in a patient with a gunshot wound. Infect Dis Clin Pract 2005;13:78-81. 


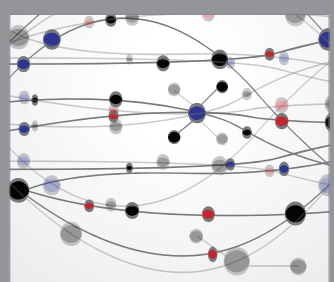

The Scientific World Journal
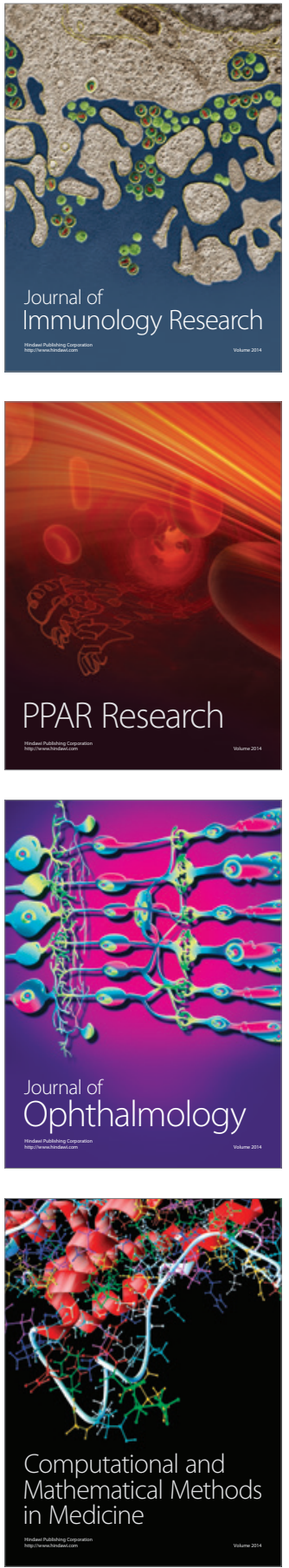

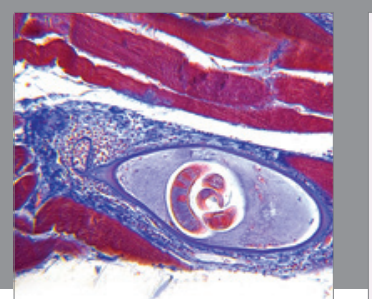

Gastroenterology Research and Practice

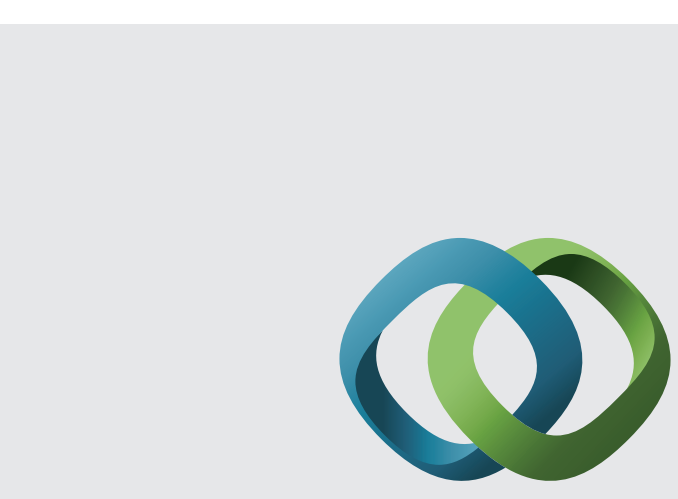

\section{Hindawi}

Submit your manuscripts at

http://www.hindawi.com
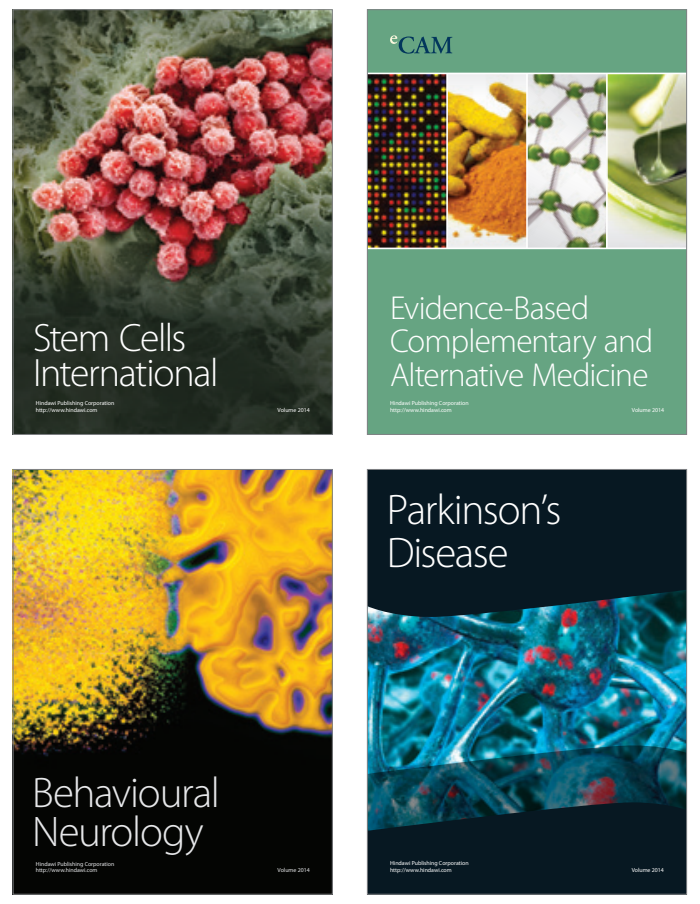
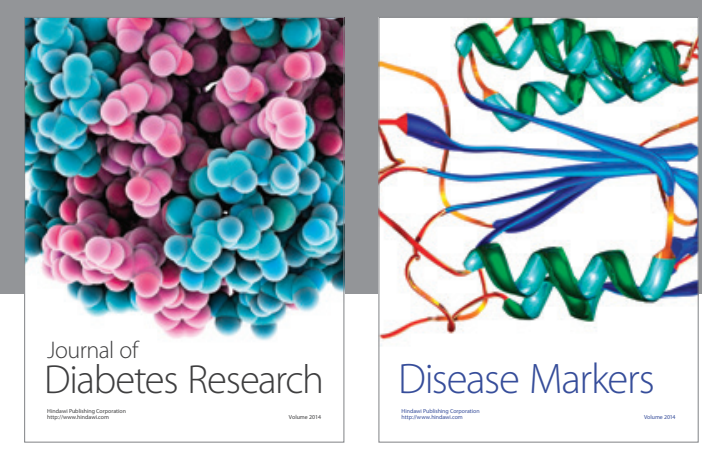

Disease Markers
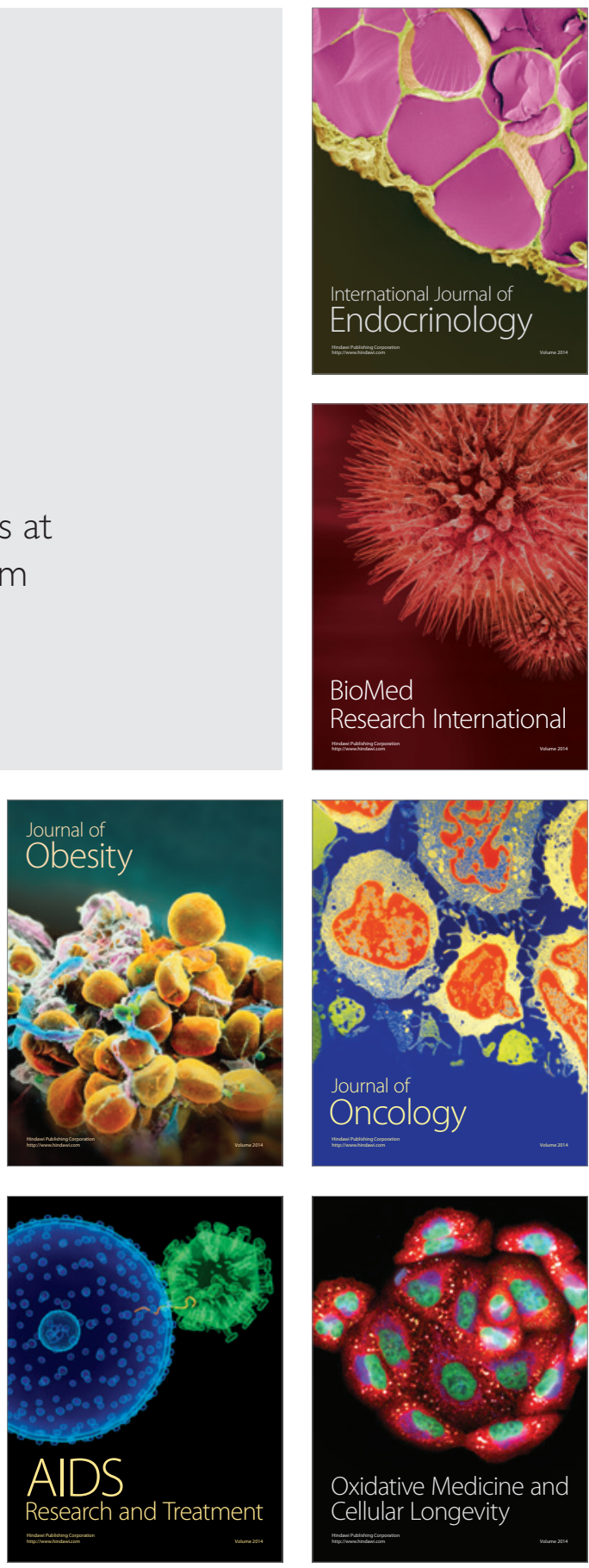